\title{
Canal Transportation- A Threat in Endodontics: A Review
}

\author{
Dr Dayananad Chole ${ }^{1}$, Dr Pratik Ashok Burad ${ }^{2}$, Dr Shashank Kundoor ${ }^{3}$, \\ Dr Srinivas Bakle ${ }^{4}$, Dr Amarnath Devagirkar ${ }^{5}$, Dr Rucha Deshpande ${ }^{6}$ \\ ${ }^{\text {I}}$ Professor and Head; Department Of Conservative Dentistry and Endodontics P.D.U Dental College; Solapur \\ ${ }^{2}$ Post Graduate Student; Department Of Conservative Dentistry and Endodontics PDU Dental College Solapur \\ ${ }^{3,4}$ Reader; Department Of Conservative Dentistry and Endodontics PDU Dental College Solapur \\ ${ }^{5,6}$ Senior Lecturer; Department Of Conservative Dentistry and Endodontics PDU Dental College Solapur
}

\begin{abstract}
The basics of root canal preparation are to enlarge the root canal for proper disinfection and to prevent reinfection with the use of irrigation agents. It also facilitates the placement of root canal filling material with proper fluid tight seal. As most root canals are curved, a high prevalence of procedural errors has been reported. Canal transportation is one of the main procedural errors. The position of physiologic terminus of the canal to a new iatrogenic location on the external root surface is transportation of the foramen. Several studies have shown that Ni-Ti instruments demonstrated less canal transportation than stainless steel files. Considerable research has been undertaken to understand the several factors related to canal transportation. In this article, we have discussed the influence of various parameters such as alloys used in the manufacture of instruments, instrument cross-section, tip, taper, and explained about clinical consequences of canal transportation.
\end{abstract}

Keywords: Root Canal Transportation, root canal treatment, NiTi, stainless steel hand instruments, crossection, taper.

\section{Introduction}

The basics of root canal preparation are to enlarge the root canal for proper disinfection and to prevent reinfection with the use of irrigation agents. It also facilitates the placement of root canal filling material with proper fluid tight seal. ${ }^{1}$

It is important to know about the biological and mechanical aspect for proper biomechanical preparation. ${ }^{2}$ If one fails to follow the objectives of biomechanical preparation, it would lead to various procedural errors during the shaping of curved root canals. These needless complications are: Perforations, block canals, ledges and apical transportation. ${ }^{2,3}$

The objectives of biomechanical preparation are difficult to achieve by using stainless steel hand instruments. ${ }^{4}$ So, various NiTi rotary instruments which have additional advantages over stainless steel hand instruments are introduced. They are quick, safe and are more accuracy oriented with mainly having lower risk of procedural errors when compared to stainless steel hand instruments. ${ }^{5}$

The selection of appropriate instruments during enlargement of curved root canals and simultaneous preservation of proper dental anatomy is a great challenge. But, there is a significant increase in the quality of root canal preparation with good results and less procedural errors, after the introduction of rotary NiTi instruments. 6

As most root canals are curved, a high prevalence of procedural errors has been reported. ${ }^{7,8}$ Canal transportation is one of the main procedural errors.

\section{Canal Transportation}

The position of physiologic terminus of the canal to a new iatrogenic location on the external root surface is transportation of the foramen. ${ }^{2}$

According to the Glossary of Endodontic Terms of the American Association of Endodontists, Canal transportation is defined as "Removal of canal wall structure on the outside curve in the apical half of the canal due to the tendency of files to restore themselves to their original linear shape during canal preparation; may lead to ledge formation and possible perforation." $"$

Apical transportation leads to uneven material removal during biomechanical preparation, decrease in the angle of curvature of curved root, long axis of the canal gets displaced, so that ultimately straightening of the curved root canals occur. Root canal instruments tends to straighten themselves in the canal so that they press against the outer side of curved canals in apical third and inner side of curved canals in middle thirds. Therefore, overpreparation occurs more towards convexity in apical thirds and more towards concavity in the middle thirds of the curved canals. ${ }^{7,10}$ This so called elbow preparation is seen when there is occurrence of apical 
transportation. Elbow preparation is reversed apical shape of canal and is very difficult for gutta percha condensation and to obtain resistance form at the apical end. ${ }^{2}$

\section{How does canal transportation occur?}

Following are the risk factors for canal transportation:

1. Improper access cavity preparation. ${ }^{11}$

2. Operator related factors.

3. Degree and radius of canal curvature: When there is smaller radius and greater degree of radius, chances of transportation is more. ${ }^{7}$

4. Insufficient and improper irrigation.

5. Use of stiffer instruments above No.20 files. ${ }^{12,13}$

6. Various techniques of biomechanical preparations. $8,12,10$

7. Different Alloys used for manufacture of shaping instruments.

8. Crossection of instruments

9. Instruments with sharp cutting tips

10. Improper interpretation of radiographs for canal curvature

\section{Undesirable outcomes after canal transportation:}

1. Loss of apical resistance and fluid tight seal due to straightening of the curved canals. There is also loss of original curvature and deviation or change in long axis of canal. These all changes may lead to apical extrusion of debris and microbes, irrigation solutions like $\mathrm{NaOCl}$ and EDTA, overextension of canal filling material. $^{8}$

2. Elbow formation or reverse apical shape formation., ${ }^{3,8}$

3. After transportation at the apex, there is formation of elliptical shape. It also gives an hour glass appearance, tear drop or foraminal rip. These greatly affects the apical seal when obturated using lateral condensation in vitro.

4. A perforation of the apical part of root canal while using rotary instruments with sharp cutting tips. ${ }^{7,8}$

\section{Apical transportation can be categorized into three types ${ }^{2}$ -}

Type I: Represents minor movement of the position of the physiologic foramen resulting in its iatrogenic relocation. If sufficient residual dentin can be maintained and the preparation above the foramen can be corrected, then some of these initially transported cases may be thoroughly cleaned, shaped and filled.

Type II: Represents moderate movement of the physiologic position of the resulting in its iatrogenic relocation on the external root surface. Apical zipping or tearing is more pronounced than Type I. A large communication with the periapical space exists in this type of transportation.

Type III: Represents severe movement of the physiologic position of the resulting in its iatrogenic relocation on the external root surface.

\section{Management of apical transportation ${ }^{2,55}$ :}

Type I: If sufficient residual dentin can be maintained and the preparation above the foramen can be corrected, then some of these initially transported cases may be thoroughly cleaned, shaped and filled.

Type II: This kind of transportation are managed by placing barrier to control bleeding and provide a backstop to pack against during obturation procedures.

Type III: A barrier technique is usually not feasible; it requires obturation as best as possible followed by corrective surgery. If it is not possible to corrct it surgically, then tooth extraction is the only alternative.

\section{Role of root canal instruments on apical transportation:}

There are some parameters of root canal instruments which can lead to apical transportation:

1. Instrument crossection:

There are variety of crossection of the root canal instruments ranging from U-shaped Profile system and light speed 1, double helical, trihelical, triangular to the parabolic , italic S-shaped crossections .

- Hikmet A. Sh. Al-Gharravi et al.,[2014] ${ }^{1}$ conducted study on BioRace, Protaper and Self adjusting file, suggested that SAF showed less transportation due to its metal meshwork and no solid metal core which makes the file compressible and modifies its shape with the canals original shape, followed by BioRace due to the alternating straight and twisted areas along the shank and elimination of screwing motion due to triangular crossection. Protaper do not have radial lands on cutting edges and have more positive rake angle that causes more apical transportation as compared to SAF and BioRace.

- Paque et al., ${ }^{15}$ found larger canal transportation with protaper rotary as compared to SAF 


\section{Instrument Taper:}

As the taper increases, the tendency towards apical transportation increases.

- Lopez Fu et al., $[2008]^{16}$ found that there was increase in the tendency for the canal transportation as the diameter of the file increases.

- Kunert GG et al., [2010] ${ }^{17}$ suggested that taper is one of the factors responsible for canal transportation and suggested that Protaper Universal F3 and F4 to be used with caution owing to taper.

- Schafer E [2003 $]^{18}$ and Ayadin C $[2012]^{19}$ suggested that due to the increase in stiffness of file, NiTi files with taper greater than 0.06 should not be used for the apical enlargement of curved root canals.

- Paque et al.o,[2005] $]^{20}$ conducted a study in simulated curved canals using protaper and RaCe, suggested that both instruments are safe to use but RaCe follows the original curvature of canal better than that of Protaper. This may be due to the variable taper along the cutting surface of Protaper.

\section{Instrument Tip:}

Some instruments have cutting tips and some have non-cutting, safe-cutting, guiding tips. Stainless steel hand cutting files have standard cutting tips which can be too aggressive because the first flut make the initial cut in apical canal transportation. ${ }^{21}$

Almost all of the NiTi rotary instruments have non-cutting tips. So, there is lower the tendency of the apical transportation when compared to stainless steel hand cutting files.

- Gutmann JL, Song YL et al.,[2004] $]^{22}$ conducted a study for three instruments using teo NiTi (GT and NiTi flex) and one stainless steel K file in curved root canals of $15^{\circ}-45^{\circ}$ curvature. Suggested that both NiTi instruments have non cutting blunt transition angle in the tip which does not engaging and screwing the dentinal wall and allow the instruments to plane the canal walls. This property of NiTi instruments make them more self centered when compared with stainless steel $\mathrm{K}$ file and lower the consequences of apical transportation.

- Wang N, Roane JB, Ponce De Leon [2003 $]^{23}$ suggested that instrumentation of curved canals is more successful with "Modified" tip instruments that is biconical shaped tips.

- Hulsmann M, Schafers F et al., [2001] ${ }^{24}$ conducted a study using HERO 642 Quantec SC rotary NiTi instruments and suggested that canal centering ability and apical transportation is lower with instruments

- Kuhn WG et al., [1997] $]^{25}$ conducted a study on NiTi and stainless steel files for the effect of tip design on root canal preparation and concluded that instruments with modified tips are very much superior in maintaining the original canal curvature, independent of whether stainless steel or NiTi hand instruments or rotary NiTi instruments were used.

- Ozer et al., [2011] $]^{26}$ compared root canal transportation induced by three rotary systems with non-cutting tips using computed tomography and found that using rotary systems with non-cutting tips did not reduce apical transportation.

- Ponce de Leon Del Bello T et al., $[\mathbf{2 0 0 3}]^{23}$ suggested that Biconical tip files (Flex-R) produced the least transportation and no ledges. Pyramidal tip files (Flex-O) produced the most transportation.

\section{Alloys for Manufacturing Endodontic Instruments:}

All the manufacturers commonly use two kinds of alloys for endodontic instruments.

1. Stainless steel

2. Nickel- Titanium Alloys

Routinely, root canal hand instrumentation is done by using stainless steel instruments. But, various studies have shown that the biomechanical preparation done by hand instruments generally lead to endodontic mishaps like elbow formation, zip formation, ledge formation and transportation of the canal. ${ }^{24}$

Civijan [1975] is the first who proposed NiTi alloys for the manufacturing of the endodontic instruments. ${ }^{27} \mathrm{NiTi}$ alloys have main property of superelasticity and before exceeding elastic limit they can flex more than stainless steel instruments. ${ }^{28,29,30,31}$

The amount of force required for the instrument to bend is the amount of force the instrument will exert and lead to more cutting on the outer curvature of canal, which results in eccentricity and transportation of canal. NiTi exerts less force than stainless steel instruments and lead to less cutting of either walls of canals. ${ }^{32}$

- Carvalho LA et al., [1999 $]^{33}$ compared stainless steel and NiTi instruments for molar root canal preparation and suggested that NiTi instruments are 2-3 times more elastic than stainless steel files when they are similarly manufactured. This property greatly helps NiTi instruments to negotiate curved canals without exerting much pressure on the lateral walls of the canals.

Carvalho also reported that even after precurving and anticurving filing, small amount of transportation could be expected from stainless steel hand instruments

- Miglani S, Gopikrishna V et al., [2004] $]^{34}$ used Kuttler's endodontic cube to compare canal centering ability of two NiTi rotary system with stainless steel hand instruments and found that stainless steel files 
produce a larger extent of movement because of their hardness which was shown to be 3-4 times higher than NiTi alloys.

- Coleman CL, Suel TA [1997] ${ }^{35}$ did analysis of NiTi versus Stainless steel instruments in resin simulated canals and reported that transportation, zipping and straightening of canals using stainless steel instruments is more than NiTi instruments.

- Javaheri HH et al.,[2007] $]^{36}$, Short JA, Morgan LA et al.,[1997] ${ }^{37}$, Metzger $Z$ et al.,[1999] ${ }^{38}$ confirmed that rotary NiTi files are better than Stainless steel hand instruments in maintaining original canal curvature, thus there is less canal transportation.

- Ida De Noronha de Ataide et al.,[2006] ${ }^{39}$ performed study to check the quality of canal preparation using stainless steel file and NiTi rotary instruments and suggested that NiTi rotary instruments produce significantly less canal transportation when compared to stainless steel hand file. This is due to the flexibility of NiTi alloys which allows instruments to follow curved canals and design of the cutting portion.

Table 1. Various studies of Instruments used in root canal preparation comparing canal transportation

\begin{tabular}{|c|c|c|}
\hline Author & Instruments used in the study & Instruments showing less canal transportation \\
\hline \multirow{3}{*}{$\begin{array}{l}\text { 1.Emmanuel Joao Nogueira leal } \\
\text { Silva et al., } 2015^{60}\end{array}$} & Twisted file Adaptive & Twisted file: lowest \\
\hline & Protaper Universal & Protaper U: Highest \\
\hline & Twisted file & \\
\hline \multirow[t]{2}{*}{ 2.Uzunoglu E et al., $2015^{64}$} & Protaper Next upto X3 & No significant difference \\
\hline & OneShape Apical 1 & \\
\hline \multirow[t]{3}{*}{ 3.Deepak Jain et al., $2015^{14}$} & OneShape file & Revo S < OneShape < Protaper Next \\
\hline & Protaper Next & \\
\hline & Revo S & \\
\hline \multirow[t]{3}{*}{ 4.Wenzhe Liu et al., $2015^{76}$} & Twisted file Adaptive & Twisted file Adaptive \\
\hline & WaveOne & \\
\hline & Protaper Next & \\
\hline \multirow[t]{2}{*}{ 5.Moghadam et al., $2014^{68}$} & Twisted file & No significant difference \\
\hline & Reciproc system & \\
\hline \multirow{3}{*}{$\begin{array}{l}\text { 6.Hikmet A Sh Al-Gharrawi et } \\
\text { al., 2014 }\end{array}$} & Self Adjusting File & BioRace \\
\hline & BioRace & \\
\hline & Protaper rotary & \\
\hline \multirow[t]{2}{*}{ 7.Varsha Tambe et al ., 2014 ${ }^{56}$} & WaveOne & WaveOne \\
\hline & OneShape & \\
\hline \multirow[t]{2}{*}{ 8.McRay B et al., 2014 ${ }^{66}$} & Protaper Universal & No significant difference \\
\hline & WaveOne & \\
\hline \multirow[t]{3}{*}{ 9.Elnaghy AM et al ., $2014^{63}$} & Protaper Next & PTN + ProGlider \\
\hline & PTN + ProGlider & \\
\hline & PTN + PathFile & \\
\hline \multirow{2}{*}{$\begin{array}{l}\text { 10.Kiumars Nazari Moghdam et } \\
\text { al., } 2014^{57}\end{array}$} & Twisted Files & Twisted Files \\
\hline & Reciproc File & \\
\hline \multirow{2}{*}{ 11.Junaid A et al., 2014 ${ }^{62}$} & WaveOne & No significant difference \\
\hline & Twisted files & \\
\hline \multirow[t]{2}{*}{ 12.Gergi R et al., 2014 ${ }^{61}$} & WaveOne & Twisted files Adaptive \\
\hline & Twisted files Adaptive & \\
\hline \multirow{3}{*}{$\begin{array}{llll}\begin{array}{l}\text { 13.Samia } \\
\text { al.,2013 }^{\text {59 }}\end{array} & \text { M. } & \text { Elsherief } & \text { et } \\
\end{array}$} & Protaper Universal & No significant difference \\
\hline & HeroShaper & \\
\hline & Revo-S & \\
\hline \multirow[t]{2}{*}{ 14.Marc Garcia et al.,2012 ${ }^{73}$} & ProFile Rotary system & No significant difference \\
\hline & RaCe Rotary system & \\
\hline & & \\
\hline
\end{tabular}


Canal Transportation- A Threat In Endodontics: A Review

\begin{tabular}{|c|c|c|}
\hline 15.Mian K Iqbal et al.,2010 & ProFile GT & No significant difference \\
\hline & GTX NiTi Rotary & \\
\hline \multirow{3}{*}{ 16.Miglani et al.,2008 ${ }^{72}$} & ProFile Rotary system & RaCe Rotary system \\
\hline & RaCe Rotary system & \\
\hline & Protaper Rotary system & \\
\hline \multirow[t]{3}{*}{ 17.Lopez FU et al.,2008 ${ }^{65}$} & Stainless steel files & K3 system \\
\hline & K3 system & \\
\hline & Reciprocating NSK handpiece & \\
\hline \multirow[t]{3}{*}{ 18.Javaheri H H et al.,2007 ${ }^{36}$} & Hero 642 & Protaper \\
\hline & $\mathrm{RaCe}$ & \\
\hline & Protaper & \\
\hline \multirow{2}{*}{ 19.Eliopoulos D et al.,2006 ${ }^{71}$} & ProFile NiTi Rotary system & ProFile NiTi Rotary system \\
\hline & Stainless steel K Flexofiles & \\
\hline \multirow[t]{2}{*}{ 20. Paque et al., $2005^{20}$} & Protaper & $\mathrm{RaCe}$ \\
\hline & $\mathrm{RaCe}$ & \\
\hline \multirow[t]{2}{*}{ 21.Iqbal M K et al.,2004 ${ }^{70}$} & ProFile Rotary system & No significant difference \\
\hline & Protaper Rotary system & \\
\hline \multirow{2}{*}{ 22.Mario Veltri et al.,2004 ${ }^{21}$} & Protaper Rotary system & No significant difference \\
\hline & GT Rotary system & \\
\hline \multirow[t]{3}{*}{$\begin{array}{l}\text { 23.Guttman JL, Song YL et al., } \\
\text { 2004 }^{22}\end{array}$} & GT NiTi Rotary & GT NiTi Rotary \\
\hline & NiTiFlex & NiTiFlex \\
\hline & Stainless steel K file & \\
\hline \multirow[t]{3}{*}{$\begin{array}{l}\text { 24.Ponce de Leon Del Bello., } \\
\text { 2003 }^{23}\end{array}$} & Biconical tip (Flex-R) & Biconical tip \\
\hline & Conical tip (Mor-Flex) & \\
\hline & Pyramidal tip (Flex-O) & \\
\hline \multirow[t]{2}{*}{$\begin{array}{lll}\begin{array}{l}\text { 25.Fernando } \\
\text { al.,2002 }^{75}\end{array} & \text { Goldberg } & \text { et } \\
\end{array}$} & $\begin{array}{l}\text { Stainless } \text { steel } \\
\text { files: } 10,15,20,25 \text { as patency files }\end{array}$ & No significant difference \\
\hline & $\begin{array}{l}\text { NiTi K files: } 10,15,20,25 \text { as } \\
\text { patency files }\end{array}$ & \\
\hline \multirow[t]{2}{*}{ 26.Hulsmann M et al., 2001 $^{24}$} & HERO 642 & No significant difference \\
\hline & Quantec SC NiTi Rotary & \\
\hline \multirow[t]{3}{*}{ 27.Frick K et al.,.1997 ${ }^{69}$} & ProFile & ProFile \\
\hline & Quantec & Quantec \\
\hline & Stainless steel hand files & \\
\hline \multirow{2}{*}{$\begin{array}{l}\text { 28.Ida De Noronha De Ataide et } \\
\text { al., } 2006^{39}\end{array}$} & NiTi files & NiTi files \\
\hline & Stainless steel files & \\
\hline
\end{tabular}

\section{Apical Transportation And Its Clinical Consequences:}

Generally, it can be stated that greater the degree of curvature and smaller the radius of curvature, there is greater the risk of canal transportation. ${ }^{7,40,41,42,43}$ There are so many studies which are concluded on the basis of evidence that almost all the canals with small curvature radius and large curvature angle showed canal transportation and it was seen when both NiTi and stainless steel hand instruments were used. ${ }^{44}$

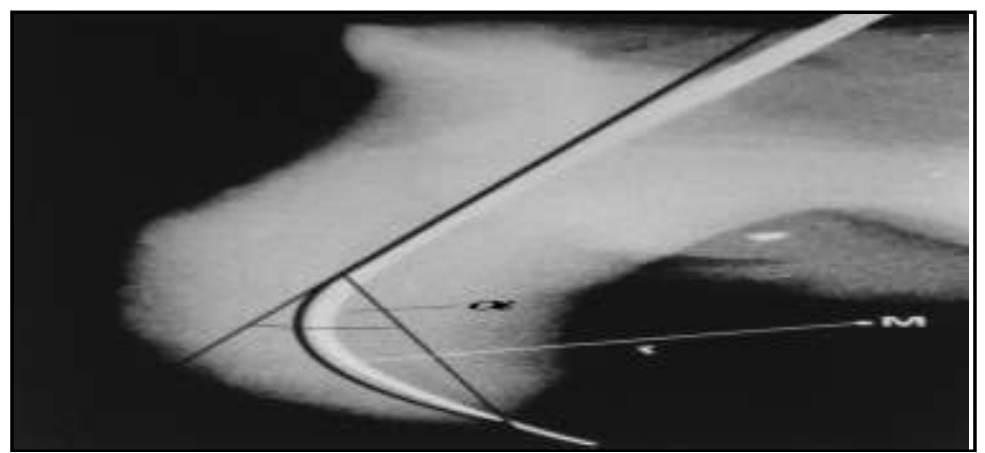

Fig.1. A curved root canal $\alpha$ is the angle of curvature; $r$ the radius of curvature; and $M$ the center of the circle describing the curved part of the root canal.

Insufficient cleaning is the main clinical result of the canal transportation. The original part of the canal remains untouched and unprepared so that insufficiently cleaned root canals are seen in cases of canal transportation. ${ }^{8}$ [Fig 2.] 


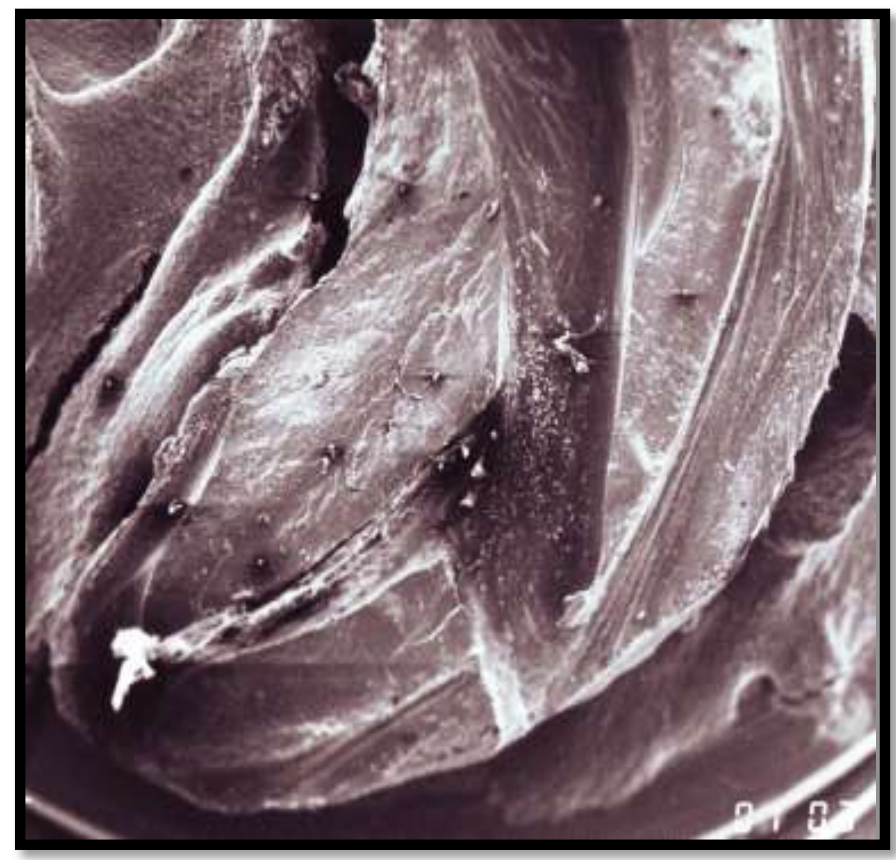

Fig. 2. Owing to canal transportation, the apical part of the root canal remains unprepared, harboring huge amounts of tissue remnants.

Canal cleanliness can be checked histologically by SEM and more recently by micro-computed tomography. ${ }^{7}$ In vitro studies showed that after instrumentation of curved root canals, both NiTi and stainless steel hand instruments left behind some uninstrumented areas in curved root canals. This is more specifically seen in apical third region of the canal. ${ }^{45,46,47}$ Nearly, 35\% of canal surface remains untouched and unprepared in both NiTi rotary and stainless steel hand instruments. ${ }^{48}$

According to the available literature, it is found that canal transportation results in increase in the amount of infected debris in the uninstrumented apical third area of the root canal and it may cause infection in this area. So, it is a bigger question whether canal transportation is the direct cause for treatment failure.

Overreduction of intracanal dentin is another consequence of canal transportation. In canal transportation, outside wall i.e. convex wall of the curved root canals in the apical third may get overinstrumented and more amount of dentin will be removed and the inside wall i.e. concave wall may remain untouched. This would lead to infected dentin with residual infected debris. ${ }^{49}$

This may be the result in the persistent post operative periapical lesion. This would cause weakening of the entire root due to the unnecessary removal of the radicular dentin. ${ }^{50}$ Thus, it reduces the fracture resistance of the enlarged root canals.

- Schafer et al.,[2006] $]^{51}$ did in vitro study to check influence of taper on fracture resistance in endodontically treated extracted teeth and concluded that there is loss of fracture resistance of about $25 \%$ after hand instrumentation (taper $=0.02$ ), 22\% after enlargement with FlexMaster (taper 0.02-0.06), and 43.7\% after preparation with GT files (taper 0.04-0.12) compared with intact control teeth. Thus, roots enlarged with instruments with greater tapers were more prone to fracture than those prepared with instruments with smaller tapers.

During root canal instrumentation, development of continuously tapered canal preparation and maintenance of proper shape form and position of apical foramen are the main objectives of biomechanical preparation. This is greatly influenced by the flexibility of instrument, crossection and diameter of instrument, location of foraminal opening, instrumentation technique and hardness of dentin. ${ }^{52}$

The occurance of upto $0.15 \mathrm{~mm}$ of root canal transportation has been considered to be acceptable, when the canal transportation is above $0.30 \mathrm{~mm}$ may have negative impact on apical seal after obturation of canal. ${ }^{7}$

Fan B et al., $[2000]^{53}$ and $\mathrm{Wu}$ MK et al., $[2000]^{54}$ performed laboratory studies where they correlated canal transportation with apical leakage in which they found that obturated curved root canals with apical $1 / 3^{\text {rd }}$ canal transportation associated with apical leakage to some extent, where as curved canals with only minimum or no transportation did not show any leakage.

Canal/apical transportation leads to-

\section{Conclusion}


1. Insufficiently cleaning of root canal

2. Over reduction of intracanal dentin

3. Reduced fracture resistance

It is also concluded that irrespective of the instrument used, canal transportation is seen with both NiTi and Stainless steel hand instrument with various crossections, taper, tip shapes and sizes.

\section{References}

[1]. Hikmet A. Sh. Al-Gharrawi ., Farah Salahalden Abbas, An evaluation of canal transportation and centering ability at different levels of root canals prepared by self-adjusting file using computed tomography (A comparative study). J Bagh College Dentistry 2014; 26(1):16-23.

[2]. Ingle's Endodontics $6^{\text {th }}$ edition : 1123-1125

[3]. Weine F, Kelly R, Lio P. The effect of preparation procedures on original canal shape and on apical foramen shape. J Endod 1975; 1: 262-6.

[4]. Schäfer E. Shaping ability of Hero 642 rotary nickel-titanium instruments and stainless steel hand K-Flexofiles in simulated curved root canals. Oral Surg Oral Med Oral Pathol Oral Radiol Endod 2001;92:215-20.

[5]. Guelzow A, Stamm O, Martus P, Kielbassa AM. Comparative study of six rotary nickel-titanium systems and hand instrumentation for root canal preparation. Int Endod J 2005;38:743-52.

[6]. Walia HM, Brantley WA, Gerstein H. An initial investigation of the bending and torsional properties of nitinol root canal files. J Endod 1988;14:346-51.

[7]. Peters OA. Current challenges and concepts in the preparation of root canal systems: A review. J Endod 2004;30:559-67.

[8]. Hu“lsmann M, Peters OA, Dummer PMH. Mechanical preparation of root canals: shaping goals, techniques and means. Endod Topics 2005: 10: 30-76.

[9]. American Association of Endodontists. Glossary of Endodontic Terms, 7th edn. Chicago: AAE, 2003

[10]. Young GR, Parashos P, Messer HH. The principles of techniques for cleaning root canals. Aust Dent J Endod 2007;52(Suppl): S52-S63.

[11]. Jafarzadeh H, Abbott PV. Ledge formation: review of a great challenge in endodontics. J Endod 2007;33:1155-1162.

[12]. Saunders EM. Hand instrumentation in root canal preparation.

[13]. Lam TV, Lewis DJ, Atkins DR, Macfarlane RH, Clarkson RM, Whitehead MG, Brockhurst PJ, Moule AJ. Changes in root canal morphology in simulated curved canals over instrumented with a variety of stainless steel and nickel titanium files. Aust Dent $\mathbf{J}$ 1999; 44: 12-19.

[14]. Deepak Jain, Ashish Medha, Neelam Patil, Nilam Kadam, Vandana Yadav, Harshal Jagadale. Shaping Ability of the Fifth Generation Ni-Ti Rotary Systems for Root Canal Preparation in Curved Root Canals using Cone-Beam Computed Tomographic: An In Vitro Study. Journal of International Oral Health 2015; 7(Suppl 1):57-61.

[15]. Paque F, Peters OA. Micro-computed tomography evaluation of the Preparation of Long Oval Root Canals in Mandibular Molars with the Self-adjusting File. J Endod 2011; 37: 517-21.

[16]. López FU, Fachin EV, Camargo Fontanella VR, Barletta FB, Só MV, Grecca FS. Apical transportation: A comparative evaluation of three root canal instrumentation techniques with three different apical diameters. J Endod 2008;34(12):1545-8.

[17]. Kunert GG, Camargo Fontanella VR, de Moura AA, Barletta FB. Analysis of apical root transportation associated with ProTaper Universal F3 and F4 instruments by using digital subtraction radiography. J Endod 2010;36(6):1052-5.

[18]. Schäfer E, Dzepina A, Danesh G. Bending properties of rotary nickel-titanium instruments. Oral Surg Oral Med Oral Pathol Oral Radiol Endod 2003;96(6):757-63.

[19]. Aydin C, Inan U, Murside G. Comparison of shaping ability of TF with PU and RS Ni-Ti instruments in simulated canals. J Dent Sci 2012;7:283-8.

[20]. Paqué F, Musch U, Hülsmann M. Comparison of root canal preparation using RaCe and Protaper rotary Ni-Ti instruments. Int Endod J 2005;38:8-16.

[21]. Veltri M, Mollo A, Pini PP, Ghelli LF, Balleri P. In vitro comparison of shaping abilities of ProTaper and GT rotary files. J Endod 2004;30:163-6.

[22]. Song YL, Bian Z, Fan B, Fan MW, Gutmann JL, Peng B. A comparison of instrument- centering ability within the root canal for three contemporary instrumentation techniques. Int Endod J 2004;37:265-71.

[23]. Ponce de Leon Del Bello T, Wang N, Roane JB. Crown-Down Tip Design and Shaping. J Endod 2003;29:513-8.

[24]. Hülsmann M, Schade M, Schafers F. A comparative study of root canal preparation with HERO642 and Quantec SC rotary Ni-Ti instruments. Int Endod J 2001;34:538-46.

[25]. Kuhn WG, Carnes DL, Clement DJ, Walker WA. Effect of tip design of nickel-titanium and stainless steel files on root canal preparation. J Endod 1997; 23: 735-738.

[26]. Ozer SY. Comparison of root canal transportation induced by three rotary systems with noncutting tips using computed tomography. Oral Surg Oral Med Oral Pathol Oral Radiol Endod 2011;111(2):244-50.

[27]. Gambill JM, Alder M, del Rio CE. Comparison of Ni-Ti and Stainless steel hand-file instrumentation using computed tomography. J Endod 1996;22:369-75.

[28]. Walia HM, Brantley WA, Gerstein H. An initial investigation of the bending and torsional properties of nitinol root canal files. J Endod 1988;14;346-51.

[29]. Serene TP. Nickel -titanium instruments: application in endodontics. EuroAmerica: Ishiyaku Inc. 1994

[30]. Cohen's. Pathways of the pulp.6th ed. 1994: 206.

[31]. Nehme WB. Elimination of intracanal metallic obstruction by abrasion using operational microscope and ultrasonics. J Endod 2001;27:365-7.

[32]. Deivanayagam Kandaswamy, Nagendrababu Venkateshbabu, Ilango Porkodi, Gali Pradeep1 Canal-centering ability: An endodontic challenge. J Conserv Dent 2009; 12: 3-9.

[33]. Carvalho LA, Bonetti I, Borges MA. A comparison of molar root canal preparation using Stainless Steel and Ni-Ti instruments. J Endod 1999;25:807-10.

[34]. Miglani S, Gopikrishna V, Parameswaran, Kandaswamy D, Krithika. Canal centering ability of two Ni-Ti rotary systems compared with SS hand instrumentation in curved canals using Kuttler's endodontic cube-An in vitro study. Endodontology 2004;16:42-8. 
[35]. Coleman CL, Suel TA. Analysis of Ni-Ti versus stainless steel instrumentation in resin simulated canals. J Endod 1997;23: 2325 .

[36]. Javaheri HH, Javaheri GH. A comparison of three Ni-Ti rotary instruments in apical transportation. J Endod 2007;33:284-6.

[37]. Short JA, Morgan LA, Baumgartner JC. A comparison of canal centering ability of four instrumentation techniques. J Endod 1997;23:503-7.

[38]. Pettiette MT, Metzger Z, Philips C, Trope M. Endodontic complications of root canal therapy performed by dental students with stainless steel K-files and nickel-titanium hand files. J Endod 1999;25:230-4.

[39]. Ida de noronha de ataide, Rahul wagle, Marina fernandes. The Quality of Canal Preparation Using Stainless Steel Hand Files and Nickel-Titanium Rotary Instruments. Endodontology 2006; 18: 25-34

[40]. Ruddle C. Cleaning and shaping the root canal system. In: Cohen S, Burns RC, eds. Pathways of the Pulp, 8th edn. St Louis: Mosby, 2002; 231-292.

[41]. Alodeh MHA, Doller R, Dummer PMH. Shaping of simulated root canals in resin blocks using the step-back technique with Kfiles manipulated in a simple in/out filling motion. Int Endod J 1989; 22: 107-117.

[42]. Alodeh MHA, Dummer PMH. A comparison of the ability of K-files and Hedstrom files to shape simulated root canals in resin blocks. Int Endod J 1989; 22: 226-235.

[43]. Greene KJ, Krell KV. Clinical factors associated with ledged canals in maxillary and mandibular molars. Oral Surg Oral Med Oral Pathol 1990; 70: 490-497.

[44]. Dummer PMH, Al-Omari MAO, Bryant S. Comparison of the performance of four files with rounded tips during shaping of simulated root canals. J Endod 1998; 24: 364-371.

[45]. Ro“dig T, Hu“lsmann M, Kahlmeier C. Comparison of root canal preparation with two rotary NiTi instruments: ProFile 0.04 and GTRotary. Int Endod J 2007; 40: 553-562.

[46]. Scha"fer E, Erler M, Dammaschke T. Comparative study on the shaping ability and cleaning efficiency of rotary Mtwo instruments. Part 2: cleaning effectiveness and shaping ability in severely curved root canals of extracted teeth. Int Endod J 2006; 39: 203-212.

[47]. Paque' F, Musch U, Hu“lsmann M. Comparison of root canal preparation using RaCe and ProTaper rotary Ni-Ti instruments. Int Endod J 2005; 38: 8-16.

[48]. Scha"fer E, Lohmann D. Efficiency of rotary nickel-titanium FlexMaster instruments compared with stainless steel hand KFlexofile. Part 2: cleaning effectiveness and instrumentation results in severely curved root canals of extracted teeth. Int Endod J 2002; 35: 514-521.

[49]. ZuoloML,Walton RE, Imura N. Histologic evaluation of three endodontic instrument/ preparation techniques. Endod Dent Traumatol 1992: 8: 125-129.

[50]. Eleftheriadis GI, Lambrianidis TP. Technical quality of root canal treatment and detection of iatrogenic errors in an undergraduate dental clinic. Int Endod J 2005; 38: 725-734

[51]. Zandbiglari T, Davids H, Scha“fer E. Influence of instrument taper on the resistance to fracture endodontically treated roots. Oral Surg Oral Med Oral Pathol 2006; 101: 126-131.

[52]. Lopes H, Elias C, Estrela C, Siqueira J. Assessment of the apical transportation of root canals using the method of the curvature radius. Braz Dent J 1998; 9(1): 39-45.

[53]. Fan B, Wu MK, Wesselink P. Leakage along warm gutta-percha fillings in the apical canals of curved roots. Endod Dent Traumatol 2000; 16: 29-33.

[54]. Wu MK, Fan B, Wesselink PR. Leakage along apical root fillings in curved root canals. Part 1: effects of apical transportation on seal of root fillings. J Endod2000; 26: 210-216.

[55]. Shiv P. Mantri, Ravi Kapur, Niharika Gupta, Charu Kapur. Type III apical transportation of root canal. Contemporary clinical dentistry 2012; 3: 134-136

[56]. Varsha Harshal Tambe, Pradnya Sunil Nagmode, Sathish Abraham, Mahendra Patait, Pratik Vinod Lahoti, Neha Jaju. Comparison of canal transportation and centering ability of rotary protaper, one shape system and wave one system using cone beam computed tomography:An in vitro study. Journal of Conservative Dentistry 2014; 17: 561-565

[57]. Kiumars Nazari Moghadam, Shahriar Shahab, Golriz Rostami. Canal Transportation and Centering Ability of Twisted File and Reciproc: A Cone-Beam Computed Tomography Assessment. IEJ Iranian Endodontic Journal 2014; 9(3): 174-179

[58]. Zahra Sadat Madani, Daryoush Goudarzipor, Azam Haddadi, Akam Saeidi, Ali Bijani. A CBCT Assessment of Apical Transportation in Root Canals.Prepared with Hand K-Flexofile and K3 Rotary Instruments. IEJ Iranian Endodontic Journal $2015 ; 10(1): 44-48$

[59]. Samia M. Elsherief, Mohamed K. Zayet, Ibrahim M. Hamouda. Cone beam computed tomography analysis of curved root canals after mechanical preparation with three nickel-titanium rotary instruments. The journal of biomedical research 2013; 279(4): 326335

[60]. Emmanuel João Nogueira Leal Silva, Michele Dias Nunes Tameirão, Felipe Gonçalves Belladonna, Aline Almeida Neves, Erick Miranda Souza, Gustavo De-Deus. Quantitative Transportation Assessment in Simulated Curved Canals Prepared with an Adaptive Movement System. July 2015; 41: 1125-1129

[61]. Gergi R, Arbab-Chirani R, Osta N, Naaman A Micro-computed tomographic evaluation of canal transportation instrumented by different kinematics rotary nickel-titanium instruments. J Endod. 2014; 40: 1223-7.

[62]. Junaid A, Freire LG, da Silveira Bueno CE, Mello I, Cunha RS. Influence of single-file endodontics on apical transportation in curved root canals: an ex vivo micro-computed tomographic study. J Endod. 2014; 40: 717-20.

[63]. Elnaghy $\mathrm{AM}^{1}$, Elsaka SE. Evaluation of root canal transportation, centering ratio, and remaining dentin thickness associated with ProTaper Next instruments with and without glide path. J Endod. 2014; 40:2053-6.

[64]. Uzunoglu E, Turker SA. Comparison of Canal Transportation, Centering Ratio by Cone-beam Computed Tomography after Preparation with Different File Systems. J Contemp Dent Pract. 2015; 16: 360-5.

[65]. López FU, Fachin EV, Camargo Fontanella VR, Barletta FB, Só MV, Grecca FS. Apical transportation: a comparative evaluation of three root canal instrumentation techniques with three different apical diameters. J Endod. 2008; 34: 1545-8.

[66]. McRay B, Cox TC, Cohenca N, Johnson JD, Paranjpe A. A micro-computed tomography-based comparison of the canal transportation and centering ability of ProTaper Universal rotary and WaveOne reciprocating files. Quintessence Int. 2014; 45: $101-8$.

[67]. Mateus Silveira Martins Hartmann, Fernando Branco Barletta, Vânia Regina Camargo Fontanella, José Roberto Vanni. Canal Transportation after Root Canal Instrumentation: A Comparative Study with Computed Tomography. JOE 2007; 33: 962-965

[68]. Nazari Moghadam K, Shahab S, Rostami G. Canal transportation and centering ability of twisted file and reciproc: a cone-beam computed tomography assessment. Iran Endod J. 2014;9(3):174-9. 
[69]. Frick K, Walia H, Deguzman J, Austin B.P. Qualitative comparison of two NiTi rotary file systems to hand filing. J Endodon 1997; 23 (4) 273(abstract).

Iqbal MK, Firic S, Tulcan J, Karabucak B, Kim S. Comparison of apical transportation between ProFile and ProTaper Ni-Ti rotary instruments. Int Endod J 2004;37:359-64.

[70]. Loizides A, Eliopoulos D, Kontakiotis E. Root canal transportation with a Ni-Ti rotary file system and stainless steel hand files in simulated root canals. Quintessence Int 2006;37:369-74.

[71]. MiglaniRL. Narayanan,Lakshmi, Rao CV. CT analysis of transportation and centering ratio using three rotary Ni-Ti files in curved root canals-An in vitro study. Endodontology 2008: 18-24.

[72]. Marc García, Fernando Duran-Sindreu, Montse Mercadé, Rufino Bueno, Miguel Roig. A Comparison of Apical Transportation between ProFile and RaCe Rotary Instruments. J Endodon 2012;38: 990-992 (abstract)

[73]. Mian K. Iqbal, Spyros Floratos, Yu Kai Hsu, DMD, Bekir Karabucak. An In Vitro Comparison of Profile GT and GTX NickelTitanium Rotary Instruments in Apical Transportation and Length Control in Mandibular Molar. Journal of Endodontics 2010; 36: $302-304$

[74]. Fernando Goldberg, Enrique J. Massone. Patency File and Apical Transportation: An In Vitro Study. J Endodon 2002; 28: 510511

[75]. Wenzhe Liu, Buling Wu. Root Canal Surface Strain and Canal Center Transportation Induced by 3 Different Nickel-Titanium Rotary Instrument Systems. J Endodon.Published Online: December 10, 2015 (abstract) 